\title{
Role of Neoadjuvant Chemotherapy in Treatment of Cervical Cancer: A Case Series of Thirty-Eight Patients Treated at Bangabandhu Sheikh Mujib Medical University in Dhaka, Bangladesh
}

\author{
Sabera Khatun1, Noor-E-Ferdous', Farzana Sharmin', Jannatul Ferdous', \\ Annekathryn Goodman ${ }^{*}$ \\ ${ }^{1}$ Bangabandhu Sheikh Mujib Medical University, Dhaka, Bangladesh \\ ${ }^{2}$ Massachusetts General Hospital, Boston, USA \\ Email: *agoodman@partners.org
}

How to cite this paper: Khatun, S., Ferdous, N., Sharmin, F., Ferdous, J. and Goodman, A. (2018) Role of Neoadjuvant Chemotherapy in Treatment of Cervical Cancer: A Case Series of Thirty-Eight Patients Treated at Bangabandhu Sheikh Mujib Medical University in Dhaka, Bangladesh. Open Journal of Obstetrics and Gynecolo$g y, 8,446-455$.

https://doi.org/10.4236/ojog.2018.85051

Received: March 4, 2018

Accepted: May 4, 2018

Published: May 7, 2018

Copyright $\odot 2018$ by authors and Scientific Research Publishing Inc. This work is licensed under the Creative Commons Attribution International License (CC BY 4.0).

http://creativecommons.org/licenses/by/4.0/

\begin{abstract}
Background: Cervical cancer is the second most common malignancy of women in Bangladesh. Surgery is the mainstay of treatment of patients with early invasive cancer confined to cervix. While the five-year survival rate after surgery for stage $\mathrm{IB}_{1}$ disease exceeds $90 \%$, it is only $60 \%-70 \%$ for stage $\mathrm{IB}_{2}$ and IIA $_{2}$ (tumor size $>4 \mathrm{~cm}$ ). To improve the outcome of treatment, two to three cycles of Neoadjuvant Chemotherapy (NACT) has been evaluated as a treatment strategy in stage $\mathrm{IB}_{2}$ and $\mathrm{IIA}_{2}$ diseases. Objectives: This study aimed to evaluate the role of neoadjuvant chemotherapy (NACT) followed by Radical Surgery (RS) among the patients with early bulky cervical cancer (Stage $\mathrm{IB}_{2}$ $\& \mathrm{IIA}_{2}$ ) to reduce the tumor size to achieve radical resectibility. Methods: This study was carried out at the Gynaecological Oncology Division of the Department of Obstetrics and Gynecology at Bangabandhu Sheikh Mujib Medical University (BSMMU) during the period July 2015 to December 2015. Thirty-eight patients with early bulky cervical cancer without any prior medical or surgical treatment received NACT using intravenous paclitaxel 175 $\mathrm{mg} / \mathrm{m}^{2}$ and cisplatin $75 \mathrm{mg} / \mathrm{m}^{2}$ followed by radical surgery. The primary outcome measure assessed the response to NACT to reduce the size of the tumor. Secondary outcome measures assessed the resectibility of tumor and compared the preoperative clinical stage to the postoperative pathological stage. This study also assessed the relationship of intraoperative and postoperative complications including the adverse effects of postoperative radiotherapy and
\end{abstract}


chemoradiotherapy. Results: Clinical response to NACT was $94.7 \%$ (84.2\% complete response $+10.5 \%$ partial response). Progressive disease was found in two cases $(5.3 \%)$. Duration of surgery was less than 2 hours in $81.6 \%$ cases and greater than 3 hours in $13.2 \%$ cases only. All women lived 5 to 10 hours away from Dhaka and could not return for in person follow-up. It was possible to get telephone follow-up on twenty-four women (63\%). Seven (29\%) had died from their cancers within one year of their surgery. Seventeen women were alive and disease free two years after completeion of their treatment. Conclusion: NACT is a feasible approach for improving the resectability of early stage bulky cervical cancer at BSMMU.

\section{Keywords}

Early Bulky Cervical Cancer, Neoadjuvant Chemotherapy (NACT), Response, Resectibility

\section{Introduction}

Cervical cancer is the fourth most common cancer in women worldwide and the seventh overall with an estimated 528,000 new cases in 2012 [1]. In Bangladesh with a population of 165 million people, the true incidence of cervical cancer is unknown due to a lack of nationwide cancer registries [2] [3]. Data from academic government hospitals suggest that cervical cancer constitutes $22 \%$ to $29 \%$ of the female cancers in Bangladesh [4]. Additionally, eighty percent of women with cervical cancer in Bangladesh present with advanced disease.

The standard treatment for early cervical cancer have traditionally comprised radical hysterectomy with lymph node dissection [5]. Surgery is the most effective therapeutic method in patients with invasive cancer confined to the cervix. The five-year survival rate after surgery for patients with stage $\mathrm{IB}_{1}$ disease exceeds $90 \%$, but is only $60 \%-70 \%$ in patients with tumors greater than $4 \mathrm{~cm}$ in size [6]. The standard has been to add postoperative radiation after surgery for women with bulky stage $\mathrm{Ib}_{2}$ and stage IIa cervical cancers. However, the lack of radiotherapy departments, especially in developing countries, the presumed high incidence of long-term complications, and the poor control of metastatic disease have brought about the development of different therapeutic approaches such as neoadjuvant chemotherapy followed by surgery or external beam radiation alone [7] [8]. To improve the therapeutic results, neoadjuvant chemotherapy (NACT) followed by radical surgery has been introduced. The definition of NACT in cervical cancer is the administration of chemotherapy for the purpose of reducing the cancer volume before the main treatment. In the late 1980s, a pilot study of NACT with cisplatin, bleomycin, and methotrexate performed for 33 patients with a tumor larger than $4 \mathrm{~cm}$ showed a response rate of $75.7 \%$ (complete response $12.1 \%$, partial response $63.6 \%$ ) on histologic examination. The anatomic sites showing a sensitive response to NACT were the vagina, cervix, and para- 
metrium, in that order [9]. In 1989, the first randomized trial investigated the role of NACT in 205 stage 1B women with cervical squamous cell carcinoma [10]. NACT enabled radical hysterectomy for inoperable bulky cervix cancer and improved the rate of complete respectability decreasing the rate of parametrial invasion. NACT was reported to reduce the pelvic recurrence rate and to increase the survival rate.

One of the motivations behind neoadjuvant chemotherapy in the treatment of cervical cancer was to reduce tumor size in order to facilitate surgical resection. This objective is an attractive potential alternative to radiation therapy in low resource countries where access to curative radiation therapy is unavailable [11] [12]. The hope has been that tumor size reduction would not only simplify surgical procedures, but also potentially transform inoperable tumors to resectable cancers. In conjunction with the reduction of lymph node metastases, neoadjuvant chemotherapy prior to surgery may decrease the need for postoperative radiotherapy or chemo-radiotherapy, minimizing long-term treatment-related complications, particularly in sexually active women. Prior to surgery, the blood supply to the tumor is uncompromised, allowing improved drug delivery and distribution. Local control might also be improved with early control of micrometastases [13].

Cervical cancer was previously thought to be chemo-resistant, and therefore chemotherapy was used only in the palliative setting for recurrent or metastatic disease [14]. However, after responses were noted to platinum-based regimens, the primary use of chemotherapy was reevaluated. Whether prior to surgery or radiotherapy, the use of neoadjuvant chemotherapy in cervical cancer has been actively studied, in multiple settings and in diverse patient populations, and has shown promise with acceptable toxicity profiles [15].

Bangabandhu Sheikh Mujib Medical University (BSMMU) is a large, public postgraduate hospital in Dhaka, Bangladesh that serves all populations of Bangladesh [16]. BSMMU has a dedicated unit for women's cancers. This study reports on the role of neoadjuvant chemotherapy in early bulky cervical cancer stage I $\mathrm{B}_{2}$ and stage II $\mathrm{A}_{2}$ in women treated at Bangabandhu Sheikh Mujib Medical University.

\section{Methods}

The study is an experimental and hospital-based descriptive study in the Gynaecological Oncology Division of Obstetrics and Gynaecology Department of Bangabandhu Sheikh Mujib Medical University, Dhaka, during the period of July 2015 to June 2016. The hospital's ethics board approved this study.

A total of 38 consecutive patients with FIGO stage I $B_{2}$ bulky or stage II $A_{2}$ tumors attending the Gynaecological Oncology outpatient unit were identified after histopathological confirmation. The patients were examined under anesthesia for clinical staging. After confirmation of the stage, patients who agreed to participate in our study were recruited after informed consent. All patients had previously untreated histologically confirmed invasive squamous cell carcinoma 
cervix. The clinical evaluation of all patients included examination under anesthesia, chest x-ray, intravenous pyelogram, cystoscopy and MRI or CT Scan. The patients were counseled about administration of neoadjuvant chemotherapy and consent was obtained. These patients were treated with one cycle of preoperative chemotherapy with Paclitaxel at the dose of $175 \mathrm{mg} / \mathrm{m}^{2}$ intravenously Day 1 and Cisplatin $75 \mathrm{mg} / \mathrm{m}^{2}$ intravenously Day 2 . Then, clinical evaluation was done to assess the reduction in the size of the tumor. The objective response to neoadjuvant chemotherapy was assessed according to the International Union Against Cancer (IUAC) criteria: 1) complete response defined as disappearance of all measurable disease, 2) partial response defined as $>50 \%$ reduction of the size of lesion in the product of the 2 maximal tumor diameters; 3 ) stable disease defined as the regression of $<50 \%$ or progression of $<25 \%$ of the tumor; and 4 ) progressive disease defined as $>25 \%$ increase in tumor size and/or the appearance of a new lesion [17]. If there was complete or partial response, patients underwent surgery after two weeks. The patients with stable and progressive disease were again treated with a second cycle of chemotherapy at the same dose. Clinical examination was again done to measure the size of tumor. All the patients with complete and partial response had type III radical hysterectomy with Bilateral Pelvic Lymph Node Dissection (BLPND). Surgery was performed within three weeks of chemotherapy. All the data were collected in a predesigned questionnaire form and the data was statistically analyzed using the Fisher's Exact test. The objective response to neoadjuvant chemotherapy was assessed according to the International Union Against Cancer Criteria. There was no control group as cancer patients cannot be observed without treatment, and during observation period the disease may spread and ethically it will not be sound.

Follow-up was performed by telephone contact as patients lived too far away from Dhaka to be able to return for check-ups. The patients came from villages outside of Dhaka. Travel time from the patients' homes to BSMMU ranged from five to ten hours.

\section{Results}

Thirty-eight consecutive patients previously untreated with histologically confirmed invasive squamous cell carcinoma cervix FIGO stage I $B_{2}$ bulky or stage II $A_{2}$ tumors attending the Gynaecological Oncology outpatient department were selected. Their ages ranged from 29 to 60 years old with a mean age of 41 years. Five were aged between 30 and 35 years, twelve were between 35 and 40 years, twelve were between 40 and 45 years, six were between 45 and 50 years, and three were between 50 and 55 years old. Table 1 outlines the education and socioeconomic status of the patients. Most patients (63\%) had a primary level of education. Twenty-six percent were illiterate. The patients were equally distributed by economic class with almost $40 \%$ in the upper middle class, $31.6 \%$ in the lower middle class, and $29 \%$ in the poor class. All 38 women had cancers with a squamous histology. Thirty-one women had Stage $\mathrm{Ib}_{2}$ and seven had Stage $\mathrm{IIa}_{2}$ cancers. Table 2 details the tumor size and stage. 
Table 1. Education and economic status of the 38 women with Stage $\mathrm{Ib}_{2}$ and $\mathrm{IIa}_{2}$ cervical cancers.

\begin{tabular}{cccc}
\hline EDUCATION & NUMBER (\%) & ECONOMIC STATUS & NUMBER (\%) \\
\hline Illiterate & $10(26.3)$ & Poor & $11(29)$ \\
Primary School & $24(63.2)$ & Lower Middle Class & $12(31.6)$ \\
Secondary School & $2(5.3)$ & Upper Middle Class & $15(39.5)$ \\
High School & $1(2.6)$ & Upper Class & 0 \\
Graduate Education & $1(2.6)$ & & \\
TOTAL & $38(100)$ & & \\
\hline
\end{tabular}

Table 2. Histopathological type, tumor size, and stage of disease for the 38 women with Stage $\mathrm{Ib}_{2}$ and $\mathrm{IIa}_{2}$ cervical cancers.

\begin{tabular}{lccccc}
\hline HISTOPATHOLOGY & $\begin{array}{c}\text { NUMBER } \\
(\%)\end{array}$ & $\begin{array}{c}\text { TUMOR } \\
\text { SIZE }\end{array}$ & $\begin{array}{c}\text { NUMBER } \\
(\%)\end{array}$ & STAGE & NUMBER (\%) \\
\hline Squamous cell grade 1 & $9(23.7)$ & $4 \mathrm{~cm}$ & $12(31.6)$ & $\mathrm{Ib}_{2}$ & $31(81.6)$ \\
Squamous cell grade 2 & $20(52.6)$ & $5 \mathrm{~cm}$ & $16(42.1)$ & $\mathrm{II} \mathrm{a}_{2}$ & $7(18.4)$ \\
Squamous cell grade 3 & $9(23.7)$ & $6 \mathrm{~cm}$ & $9(23.7)$ & & \\
& & $>6 \mathrm{~cm}$ & $1(2.6)$ & & \\
\hline
\end{tabular}

Of the 38 patients who received NACT, $81.5 \%$ experienced a complete clinical response. Four women who experience a partial response were treated with both NACT and radiotherapy prior to surgery. One woman had no change in her tumor size. She underwent surgery with the successful removal of her cancer. Two women (5.3\%) had chemo-resistant disease with progression. They underwent palliative radiotherapy for tumor control. Table 3 details response rates, duration of surgery, and blood loss at surgery. Response to treatment correlated with surgical effort. Blood loss was greater than one liter in patients with partial responses compared to complete responses ( $p$-value $=0.035$ ). Additionally duration of surgery was related to NACT response. Patients whose cancers responded completely to NACT had shorter surgeries compared to only a partial response $(p$-value $=0.029)$. There was no correlation between tumor size and stage and response to NACT ( $p$-value $=0.321$ for size; $p$-value $=0.569$ for stage). Moreover, histologic grade of the squamous cell cancers did not correlation with chemotherapy response. Twenty-five percent of grade 1, forty-seven percent of grade 2, and 28 percent of grade 3 tumors had a complete response to NACT $(p$-value $=0.271)$.

For the 36 women who underwent radical hysterectomies after NACT (34 women) and NACT and radiotherapy (two women), residual invasive cancer was present in $94.7 \%$ of specimens (34 patients) and absent in only two patients. Lymphovascular space invasion was identified in nine hysterectomy specimens.

Telephone follow-up with the patient or their families was achieved for 24 patients (63\%). Table 4 details the known outcomes. Seventeen women are alive 
Table 3. Treatment history and response for the 38 women with Stage $\mathrm{Ib}_{2}$ and $\mathrm{IIa}_{2}$ cervical cancers.

\begin{tabular}{|c|c|c|c|c|c|c|c|}
\hline RESPONSE & $\begin{array}{c}\text { NUMBER } \\
(\%)\end{array}$ & METHOD & $\begin{array}{c}\text { NUMBER } \\
(\%)\end{array}$ & $\begin{array}{c}\text { SURGERY } \\
\text { DURATION } \\
\text { (hours) }\end{array}$ & $\begin{array}{c}\text { NUMBER } \\
(\%)\end{array}$ & $\begin{array}{l}\text { BLOOD } \\
\text { LOSS }\end{array}$ & $\begin{array}{c}\text { NUMBER } \\
(\%)\end{array}$ \\
\hline COMPLETE & $31(81.6)$ & $\begin{array}{c}\text { NACT } \\
\text { SURGERY }\end{array}$ & $34(94.7)$ & 2 & $19(50)$ & 1 liter & $27(71.1)$ \\
\hline PARTIAL & $4(10.5)$ & $\begin{array}{c}\text { NACT } \\
\text { SURGERY } \\
\text { RADIOTHERAPY }\end{array}$ & $2(5.3)$ & 2.5 & $4(10.5)$ & 1.5 liter & $2(5.3)$ \\
\hline STABLE & $1(2.6)$ & $\begin{array}{c}\text { NACT } \\
\text { SURGERY }\end{array}$ & & 3 & $13(34.2)$ & 2 liter & $7(18.4)$ \\
\hline PROGRESSION & $2(5.3)$ & $\begin{array}{c}\text { NACT } \\
\text { PALLIATIVE } \\
\text { RADIOTHERAPY }\end{array}$ & & No surgery & $2(5.3)$ & & \\
\hline
\end{tabular}

Table 4. Follow-up information and outcomes for the 38 women with Stage $\mathrm{Ib}_{2}$ and $\mathrm{IIa}_{2}$ cervical cancers.

\begin{tabular}{cc} 
Outcome & Number of patients (\%) \\
\hline Contacted patient or family & $24(63 \%)$ \\
Alive with no evidence of recurrence & $17(71 \%$ of those contacted $)$ \\
Alive with recurrence & 0 \\
Died within six months of treatment & 3 \\
Died between six and twelve months after treatment & 3 \\
Died after one year from treatment & 1 \\
Total died & $7(29 \%$ of those contacted $)$ \\
Lost to follow-up & $14(37 \%)$ \\
TOTAL & 38 \\
\hline
\end{tabular}

and have no clinical evidence of recurrence. Seven women died from recurrences of their cancers $(29 \%)$. All seven women received postoperative radiation therapy. They all died within one year of completion of treatment. Specifically the patients succumbed from their cancers one month [1], four months [1], five months [1], six months [2], seven months [1] and twelve months [1] after treatment from cancer-related illness.

\section{Discussion}

Our study of thirty-eight women with bulky stage $\mathrm{Ib}_{2}$ and Stage $\mathrm{IIa}_{2}$ confirms the findings of other centers that neoadjuvant chemotherapy prior to surgery, improves the ability to perform radical surgery, and reduces blood loss and time in surgery. The chemotherapy regimen used at BSMMU with cisplatin and paclitaxel is currently thought to be one of the most efficacious [18] [19]. The hope is that neoadjuvant chemotherapy (NACT) will improve prognosis of patients with 
early bulky cervical cancer. The platinum/paclitaxel combination is now the preferred regimen in the neoadjuvant setting and preliminary data indicate that dose-dense regimens are feasible and effective (overall response rate: $67.8 \%$ 87\%) [20]. It is unclear from our experience at BSMMU whether NACT improves survival. Our numbers are small and follow-up is challenging in Bangladesh as patients have to travel great distances for therapy and they rarely return for follow-up. Other authors have also noted the challenges of poor clinic follow-up in Bangladesh due to complex socioeconomic factors [21].

In 1999, the National Cancer Institute announcement modified the paradigm of locally advanced cervical cancer (LACC) treatment toward concurrent chemoradiation, after the publication of five randomized trials that demonstrated a survival advantage with the addition of cisplatin-based chemotherapy to radiotherapy alone [22] [23] [24] [25] [26].

Since then, many systematic reviews and meta-analyses have analyzed the overall benefit of NACT because of the range of therapies and post chemotherapy treatment [27] [28] [29]. The results have been mixed. Some meta-analyses showed NACT followed by surgery resulted in a reduction in the risk of death by $35 \%$ with a gain of $14 \%$ in the 5 -year survival compared with radiotherapy. In a Cochrane meta-analysis, overall survival and progression-free survival were significantly improved with NACT followed by surgery versus surgery alone (23\% reduction in the risk of death) [30]. In a prospective, randomized trial, there was no difference in recurrence or death rates for those patients who received NACT versus those who did not before undergoing a radical hysterectomy [31]. Most recently, a prospective, randomized trial of neoadjuvant chemotherapy followed by radical surgery versus standard cisplatin-based chemoradiation for patients with bulky local cervical cancers showed a superior disease free interval for the cisplatin-bases concurrent chemo radiation arm $(76.7 \%$ versus $69.3 \%$ disease-free 5-year survival) [32].

In Bangladesh, 80\% women present with advanced stage (Stage III - IV) cervical cancer, and this is fatal in this country [4]. Radiotherapy is a scarce resource leading to a long waiting list of patients needing to be treated. The strategy of NACT has been adopted in Bangladesh to overcome the scarcity of radiation therapy [33]. The primary objectives of NACT in the treatment of cervical cancer include improvement in tumor characteristics to allow prolonged disease-free and overall survival, and a reduction in the need for radiation therapy. Our study of 38 women with locally bulky cancers again supports the use of NACT to allow 36 of these women to undergo surgery. However, $29 \%$ of the 24 women who had telephone follow-up were dead from their cancers within one year. The data from multiple, heterogeneous studies have consistently reported a pathologic response to NACT but long term survival differences between NACT followed by surgery and/or radiation versus conventional therapy are mixed [27]. NACT clearly allows previously unresectable cancers to be surgically removed, an important strategy to at least reduce symptoms and allow pelvic control of the cancer. More long-term outcome data from LMICs, where radiation 
may not be readily available, is necessary to further evaluate this treatment strategy.

\section{References}

[1] Globocan (2012) Estimated Cancer Incidence, Mortality, and Prevalence Worldwide 2012 International Agency for Research on Cancer.

http://globocan.iarc.fr/Pages/fact_sheets_cancer.aspx

[2] Hussain, S.M.A. (2013) Comprehensive Update on Cancer Scenario of Bangladesh. South Asian Journal of Cancer, 2, 279-284. https://doi.org/10.4103/2278-330X.119901

[3] Worldometer (2018) Bangladesh Population. http://www.worldometers.info/world-population/bangladesh-population/

[4] Hussain, S.A. and Sullivan, R. (2013) Cancer Control in Bangladesh. Japanese Journal of Clinical Oncology, 43, 1159-1169. https://doi.org/10.1093/jico/hyt140

[5] Hwang, Y.Y., Moon, H., Cho, S.H., Kim, K.T., Moon, Y.J., Kim, S.R., et al. (2001) Ten-Year Survival of Patients with Locally Advanced, Stage Ib-IIb Cervical Cancer after Neoadjuvant Chemotherapy and Radical Hysterectomy. Gynecologic Oncology, 82, 88-93. https://doi.org/10.1006/gyno.2001.6204

[6] Liu, Y.M., Ni, L.Q., Wang, S.S., Lv, Q.L., Chen, W.J. and Ying, S.P. (2018) Outcome and Prognostic Factors in Cervical Cancer Patients Treated with Surgery and Concurrent Chemoradiotherapy: A Retrospective Study. World Journal of Surgical Oncology, 16, 18. https://doi.org/10.1186/s12957-017-1307-0

[7] Grover, S., Xu, M.J., Yeager, A., Rosman, L., Groen, R.S., Chackungal, S., Rodin, D., Mangaali, M., Nurkic, S., Fernandes, A., Lin, L.L., Thomas, G. and Tergas, A.I. (2015) A Systematic Review of Radiotherapy Capacity in Low- and Middle-Income Countries. Frontiers in Oncology, 4, 1-11. https://doi.org/10.3389/fonc.2014.00380

[8] Chuang, L., Kanis, M.J., Miller, B., Wright, J., Small Jr., W. and Creasman, W. (2016) Treating Locally Advanced Cervical Cancer With Concurrent Chemoradiation without Brachytherapy in Low-Resource Countries. American Journal of Clinical Oncology, 39, 92-97. https://doi.org/10.1097/COC.0000000000000222

[9] Scarabelli, C., Zarrelli, A., Gallo, A. and Visentin, M.C. (1995) Multimodaltreatment with Neoadjuvantintraarterial Chemotherapy Andradical Surgery in Patients with Stage IIIB-IVA Cervical Cancer: A Preliminary Study. Cancer, 76, 1019-1026. https://doi.org/10.1002/1097-0142(19950915)76:6<1019::AID-CNCR2820760616>3. $\underline{0 . \mathrm{CO} ; 2-4}$

[10] Sardi, J., Sananes, C., Giaroli, A., Maya, G. and di Paola, G. (1990) Neoadjuvant Chemotherapy in Locally Advanced Carcinoma of the Cervix Uteri. Gynecologic Oncology, 38, 486-493. https://doi.org/10.1016/0090-8258(90)90096-4

[11] Uddin, A.F.M.K., Khan, Z.J., Islam, J. and Mahmud, A. (2013) Cancer Care Scenario in Bangladesh. South Asian Journal of Cancer, 2, 102-104. https://doi.org/10.4103/2278-330X.110510

[12] Sharma, V., Kerr, S.H., Kawar, Z. and Kerr, D.J. (2011) Challenges of Cancer Control in Developing Countries; Current Status and Future Perspective. Future Oncology, 7, 1213-1222.

[13] Therasse, P., Mauriac, L., Welnicka-Jaskiewicz, M., Bruning, P., Cufer, T., Bonnefoi, H., Tomiak, E., Pritchard, K.I., Hamilton, A., Piccart, M.J. EORTC (2003) Final Results of a Randomized Phase III Trial Comparing Cyclophosphamide, Epirubicin, and Fluorouracil with a Dose-Intensified Epirubicin and Cyclophosphamide + Fil- 
grastim as Neoadjuvant Treatment in Locally Advanced Breast Cancer: An EORTCNCIC-SAKK Multicenter Study. Journal of Clinical Oncology, 21, 843-850. https://doi.org/10.1200/JCO.2003.05.135

[14] Kawano, M., Mabuchi, S., Matsumoto, Y., Sasano, T., Takahashi, R., Kuroda, H., Kimura, T., et al. (2015) The Significance of G-CSF Expression and Myeloid-Derived Suppressor Cells in the Chemoresistance of Uterine Cervical Cancer. Scientific Reports, 5, Article No. 18217.

[15] Markman, M. (2014) Advances in Cervical Cancer Pharmacotherapies. Expert Review of Clinical Pharmacology, 7, 219-223. https://doi.org/10.1586/17512433.2014.884924

[16] Bangabandhu Sheikh Mujib Medical University (BSMMU) (2018). http://www.bsmmu.edu.bd/

[17] Therasse, P., Arbuck, S.G., Eisenhauer, E.A., Wanders, J., Kaplan, R.S., Rubinstein, L., Verweij, J., Van Glabbeke, M., van Oosterom, A.T., Christian, M.C., et al. (2000) New Guidelines to Evaluate the Response to Treatment in Solid Tumors. JNCI: Journal of the National Cancer Institute, 92, 205-216. https://doi.org/10.1093/jnci/92.3.205

[18] Chou, H.H., Huang, H.J., Lin, H., Yang, L.Y., Hsueh, S., Liu, F.Y., Liou, Y.L., Liou, J.D., Chen, M.Y., Chao, A., Lin, G., Chang, T.C. and Lai, C.H. (2014) Phase I Dose-Escalation Study of Weekly Paclitaxel and Cisplatin Followed by Radical Hysterectomy in Stages IB2 and IIA2 Cervical Cancer. American Journal Clinical Oncology, 40, 241-249.

[19] Duenas-Gonzalez, A., Lopez-Graniel, C., Gonzalez-Enciso, A., Cetina, L., Rivera, L., Mariscal, I., et al. (2003) A Phase II Study of Multimodality Treatment for Locally Advanced Cervical Cancer: Neoadjuvant Carboplatin and Paclitaxel Followed by Radical Hysterectomy and Adjuvant Chemoradiation. Annals of Oncology, 14, 1278-1284. https://doi.org/10.1093/annonc/mdg333

[20] Lapresa, M., Parma, G., Portuesi, R. and Colombo, N. (2015) Neoadjuvant Chemotherapy in Cervical Cancer: An Update. Expert Review of Anticancer Therapy, 15, 1171-1181. https://doi.org/10.1586/14737140.2015.1079777

[21] Islam, S.M.S., Lechner, A., Ferrari, U., Froeschl, G., Alam, D. S., Holle, R., Niessen, L.W., et al. (2014) Mobile Phone Intervention for Increasing Adherence to Treatment for Type 2 Diabetes in an Urban Area of Bangladesh: Protocol for a Randomized Controlled Trial. BMC Health Services Research, 14, 586. https://doi.org/10.1186/s12913-014-0586-1

[22] Peters, W.A., Liu, P.Y., Barrett, R.J., et al. (2000) Concurrent Chemotherapy and Pelvic Radiation Therapy Compared with Pelvic Radiation Therapy Alone as Adjuvant Therapy after Radical Surgery in High-Risk Early-Stage Cancer of the Cervix. Journal of Clinical Oncology, 18, 1606-1613. https://doi.org/10.1200/JCO.2000.18.8.1606

[23] Keys, H.M., Bundy, B.N., Stehman, F.B., et al. (1999) Cisplatin, Radiation, and Adjuvant Hysterectomy Compared with Radiation and Adjuvant Hysterectomy for Bulky Stage IB Cervical Carcinoma. New England Journal of Medicine, 340, 1154-1161. https://doi.org/10.1056/NEJM199904153401503

[24] Rose, P.G., Bundy, B.N., Watkins, E.B., et al. (1999) Concurrent Cisplatin-Based Radiotherapy and Chemotherapy for Locally Advanced Cervical Cancer. New England Journal of Medicine, 340, 1144-1153. https://doi.org/10.1056/NEJM199904153401502

[25] Morris, M., Eifel, P.J., Lu, J., et al. (1999) Pelvic Radiation with Concurrent Che- 
motherapy Compared with Pelvic and Para-Aortic Radiation for High-Risk Cervical Cancer. New England Journal of Medicine, 340, 1137-1143. https://doi.org/10.1056/NEJM199904153401501

[26] Whitney, C.W., Sause, W., Bundy, B.N., et al. (1999) Randomized Comparison of Fluorouracil plus Cisplatin versus Hydroxyurea as an Adjunct to Radiation Therapy in Stage IIBYIVA Carcinoma of the Cervix with Negative Para-Aortic Lymph Nodes: A Gynecologic Oncology Group and Southwest Oncology Group Study. Journal of Clinical Oncology, 17, 1339-1348.

https://doi.org/10.1200/JCO.1999.17.5.1339

[27] (NACT) Neoadjuvant Chemotherapy for Locally Advanced Cervical Cancer Meta-analysis Collaboration (2003) Neoadjuvant Chemotherapy for Locally Advanced Cervical Cancer: A Systematic Review and Meta-Analysis of Individual Patient Data from 21 Randomized Trials. European Journal of Cancer, 39, 2470-2486.

[28] Osman, M. (2014) The Role of Neoadjuvant Chemotherapy in the Management of Locally Advanced Cervix Cancer: A Systematic Review. Oncology Reviews, 28, 250. https://doi.org/10.4081/oncol.2014.250

[29] Rydzewska, L., Tierney, J., Vale, C.L. and Symonds, P.R. (2010) Neoadjuvant Chemotherapy plus Surgery versus Surgery for Cervical Cancer. Cochrane Database System Review, CD007406.

[30] Kokka, F., Bryant, A., Brockbank, E., Powell, M. and Oram, D. (2015) Hysterectomy with Radiotherapy or Chemotherapy or Both for Women with Locally Advanced Cervical Cancer. Cochrane Database Systematic Reviews, 7, CD010260.

[31] Eddy, G.L., Bundy, B.N., Creasman, W.T. and Soirtos, N.M. (2007) Treatment of ("Bulky") Stage Ib Cervical Cancer with or without Neoadjuvant Vincristine and Cisplatin Prior to Radical Hysterectomy and Pelvic/Para-Aortic Lymphadenectomy: A Phase III Trial of the Gynecologic Oncology Group. Gynecologic Oncology, 106, 362-369. https://doi.org/10.1016/j.ygyno.2007.04.007

[32] Gupta, S., Maheshwari, A., Parab, P., Mahantshetty, U., Hawaldar, R., Sastri Chopra, S., Kerkar, R., Engineer, R., Tongaonkar, H., Ghosh, J., Gulia, S., Kumar, N., Shylasree, T.S., Gawade, R., Kembhavi, Y., Gaikar, M., Menon, S., Thakur, M., Shrivastava, S. and Badwe, R. (2018) Neoadjuvant Chemotherapy Followed by Radical Surgery versus Concomitant Chemotherapy and Radiotherapy in Patients with Stage IB2, IIA, or IIB Squamous Cervical Cancer: A Randomized Controlled Trial. Journal of Clinical Oncology.

[33] Haque, N., Uddin, A.F.M.K., Dey, B.R., Islam, F. and Goodman, A. (2017) Challenges to Cervical Cancer Treatment in Bangladesh: The Development of a Women's Cancer Ward at Dhaka Medical College Hospital. Gynecologic Oncology Reports, 21, 67-72. https://doi.org/10.1016/j.gore.2017.06.001 